\title{
Linguagens do corpo: dimensões expressivas e possibilidades educativas da ginástica e da dança
}

Livia Tenorio Brasileiro * e Luciana Pedrosa Marcassa ${ }^{* *}$

Resumo: O presente texto busca refletir sobre a dança e a ginástica como duas manifestações culturais que, entre outras, constituem o universo das linguagens do corpo, analisando os sentidos e os significados contidos em suas dimensões expressivas e apontando algumas orientaçōes pedagógicas, particularmente para o campo da educação física.

Palavras-chave: educação física; dança; ginástica.

Body languages: expressive dimensions and educational possibilities for gymnastics and dance

Abstract: The present text is aimed at stimulating a reflection on dance and gymnastics as two different cultural manifestations that, like others, belong to the universe of the body languages. The authors analyze the senses and meanings in the expressive dimension of dance and gymnastics and point to some pedagogical orientations, especially useful to the field of Physical Education.

Key words: physical education; dance; gymnastics.

\section{Introdução}

A educação física é um campo de conhecimentos e uma prática pedagógica responsável pela produção científica e pela sistematização do conhecimento, bem como pelo acesso, pela prática, pelo ensino e pelo aprendizado do conjunto das manifestações da cultura corporal (esporte, dança, ginástica, jogo, lutas, etc.) que se podem fazer presentes em diferentes espaços de intervenção (escolas, clubes, academias, clínicas de saúde, centros culturais e demais equipamentos de lazer).

* Professora do Departamento de Educação Física da Universidade Estadual da Paraíba, Brasil. livtb@hotmail.com

* Professora da Faculdade de Educação Física da Universidade Federal de Goiás, Brasil. lumarcassa@hotmail.com 
$\mathrm{Na}$ escola, a educação física deve colocar à disposição de todos os grupos e classes sociais os saberes, as experiências, as produçôes simbólicas e materiais que cercam o conjunto das práticas e das manifestaçôes corporais, de modo a democratizá-las como riquezas culturais, como bens socialmente produzidos. E, pelo lazer, ela deve oferecer ao conjunto da sociedade novas referências teóricas e práticas que enriqueçam o modo de olhar, experimentar, sentir, tocar e de relacionar-se com o corpo, criando e recriando diferentes formas de convivência, de aprendizagem e de intercâmbio cultural.

Entretanto, temos visto, na sociedade contemporânea, um discurso hegemônico sobre o corpo considerado como santuário do músculo, como emblema da cultura da aparência, como modelo de perfeição e identidade tido como universalmente aceito e desejado, reforçando a imagem do sujeito narcísico. E para o alcance desse ideal de corpo, diante de tantas tecnologias e pedagogias para o controle e a modificação dos corpos, a educação física, que desde suas origens partilha de uma concepção dualista, mecanicista, organicista e individualista de educação do corpo, integra-se aos mecanismos de ampliação da obsessão, da opressão e da padronização dos indivíduos. Nas sociedades ocidentais modernas, ela participa de um processo chamado de "descorporalização", que significa, segundo Gonçalves (1994), que o ser humano se tornou independente da comunicação empática de seu corpo com o mundo, reduzindo sua capacidade de percepção sensorial, aprendendo a controlar seus afetos, transformando a livre manifestação de seus sentimentos em expressões e gestos formalizados, permitindo um crescente processo de manipulação do corpo, com conseqüências graves.

Diante desse quadro, como pode a educação física contribuir para a reflexão dos atuais modelos de corpo e práticas corporais que vigoram na sociedade, possibilitando ao conjunto desta novas experiências e visões sobre o corpo, sobre a gestualidade e sobre as práticas corporais?

Talvez seja preciso criar e sistematizar novas possibilidades de educação do corpo que subsidiem o trabalho com as manifestaçôes da cultura corporal, tendo em vista ampliar as capacidades humanas e as formas de comunicação entre os indivíduos e com o mundo.

Um projeto ampliado de formação humana, que valorize a dimensão corporal e as linguagens que dela derivam, requer que as atitudes e as representações relacionadas ao corpo não sejam determinadas pelos interesses do mercado, nem pelo desrespeito abusivo aos seus limites, transgredidos pela comercialização e pela banalização da imagem do corpo, cujas projeções e promessas tornam ainda mais frustrados os sujeitos-coisificados.

Esse projeto de educação demanda que, no campo acadêmico da educação física, sejam relativizadas as explicaçôes da fisiologia do exercício e da medicina 
do esporte como únicas verdades no assunto, até porque têm sido elas as responsáveis pelo fornecimento de conhecimentos, instrumentos e técnicas de manipulação, mutilação, artificialização e coisificação do corpo.

Imprescindível, portanto, é pensar sobre o corpo, os movimentos, os gestos, os comportamentos, assim como o esporte, a ginástica, a dança e as demais práticas corporais, como manifestaçóes culturais expressivas, como linguagens participantes da vida social, na construção de saberes, valores, ações, sentidos e significados, comportamentos e relaçôes humanas. Ao lidar com a cultura corporal na escola, a educação física deve explorar tudo aquilo que se refere ao corpo humano, ao seu movimento e às práticas corporais ou, mais especificamente, às linguagens corporais. Seu objetivo

é desenvolver uma reflexão pedagógica sobre o acervo de formas de representação do mundo que o homem tem produzido no decorrer da história, exteriorizadas pela expressão corporal: jogos, danças, lutas, exercícios ginásticos, esporte, malabarismo, contorcionismo, mímica e outros, que podem ser identificados como formas de representação simbólica de realidades vividas pelo homem, historicamente criadas e culturalmente desenvolvidas (Coletivo de Autores, 1992, p. 38).

Diante dessa perspectiva, o diálogo entre Educação e Arte nos parece fecundo para refletir sobre as dimensóes expressivas e educativas presentes no universo das atividades corporais, especialmente a ginástica e a dança, dimensões que compõem, portanto, o conjunto de conhecimentos e o trabalho pedagógico da Educação Física na escola.

Entendendo que a Arte faz parte do ser humano; está marcadamente em todos os seus processos de criação e recriação do mundo, através de diversas manifestações culturais (Barbosa, 1999); e se (re)produz nas práticas sociais, então, as práticas corporais só se tornam passíveis de apreensão em processos de mediação entre as pessoas, tornando-se um espaço privilegiado de Educação.

Em se tratando da democratização da cultura, ou seja, do acesso aos bens simbólicos, como já apontamos anteriormente, o diálogo entre Arte e Educação deve ter como foco a intervenção no espaço educacional. Cabe à escola fornecer novas referências que permitam sair da visão utilitarista de conhecimento, possibilitando o entendimento da produção cultural, que é bastante diversificada em suas formas e em seus processos de criação e apresentação, não só para o desfrute, o prazer e o enriquecimento humano, mas também para compreender e avaliar; para aceitar ou não os novos processos e produções postos na sociedade. 
Nesse sentido, pensar as dimensões expressivas e educativas a partir da relação entre Arte e Educação significa contribuir para a produção de conhecimentos de que a Educação Física já vem se apropriando, mas pode avançar ainda mais. Assim, se queremos construir novas possibilidades pedagógicas para o trabalho com a dança e a ginástica na escola, o diálogo entre a educação física, a arte e a educação nos parece fundamental, uma vez que ele nos permite reconhecê-las (a ginástica e a dança) como manifestações da cultura corporal que integram o universo das linguagens artísticas, compondo um registro de saberes, sentidos, significados que permeiam a realidade complexa em que vivemos. Refletir sobre as narrativas (escrita/dramaturgia) culturalmente construídas em torno da dança e da ginástica pode nos revelar os processos e os movimentos que consolidam a expressão corporal como linguagem, que na ação educativa deverá ser elucidada.

\section{A educação física e as linguagens do corpo}

$\mathrm{Na}$ medida em que a educação física lida, pedagogicamente, com expressões da cultura, então, pela educação do corpo também se difunde uma determinada ordem cultural, da qual a cultura corporal é constitutiva e constituinte.

Isso significa que a educação física compartilha de um projeto de educação corporal que está presente em todos os lugares e momentos da vida humana, colaborando para a incorporação de hábitos, comportamentos e referências sobre o corpo e a gestualidade que vão formando e configurando sujeitos e coletividades, delineando normas sociais que circunscrevem cada sociedade. Como diria Soares:

Os corpos são educados por toda a realidade que os circunda, por todas as coisas com as quais convivem, pelas relaçôes que se estabelecem em espaços definidos e delimitados por atos de conhecimento. Uma educação que se mostra como face polissêmica e se processa de um modo singular: dá-se não só por palavras, mas por olhares, gestos, coisas, pelo lugar onde vivem (2001, p.110).

Também para Rodrigues (1987), os hábitos corporais são aprendidos e transmitidos pela educação. É por ela que se incutem nos indivíduos os princípios que explícita ou disfarçadamente são comuns aos membros de uma sociedade; por meio da educação faz-se de cada criança um membro da sociedade, sobretudo fazendo-a abrir mão de sua autonomia corporal para incorporar marcas próprias de sua sociedade e de seu tempo. 
Estamos convencidas, como Gonçalves (1994), de que o corpo é, sobretudo, um meio de comunicação empática com o mundo, participante ativo e permanente dos processos de sociabilidade, da produção material e simbólica e das experiências culturais. É o que afirma também Rodrigues, para quem:

[...] um caminho possível para compreender o corpo e as práticas corporais é considerá-los como pertencendo ao universo dos símbolos e da comunicação. Partes do corpo, posturas, gestos, contatos, interação corporal, remetem a conteúdos implícitos, são significados de elaboração secundária, com propósitos não necessariamente corporais (1987, p.93).

Com isso, pensamos que mesmo as expressóes corporais mais vinculadas ao funcionamento biológico do organismo são, na verdade, mediadas e construídas pela cultura, como é o caso das perturbações do aparelho digestivo, dos limites humanos para dor, sono, fome, sede, etc. Portanto, compactuamos com a idéia de que "símbolo" é a palavra-chave que nos ajudaria a compreender essas questôes, pois

[...]o corpo, os gestos e as práticas corporais devem ser interpretados e decifrados, mais ou menos, como se decifram os símbolos do inconsciente - pois desde cedo aprendemos a absorvê-los de modo tão consciente como aquele pelo qual adquirimos as regras do idioma que falamos (Rodrigues, 1987, p.93).

Porém, como informa o próprio autor, a linguagem corporal e os conteúdos significativos da gestualidade não são universais. Gestos, comportamentos e formas de comunicação não-verbais variam de cultura para cultura, ainda que os indivíduos tenham em vista os mesmos objetivos com seus atos. Assim, as maneiras de chamar alguém, de concordar, cumprimentar, indicar objetos, despedir-se, expressar contentamento, cumplicidade ou desconfiança são distintas e, muitas vezes, exprimem sentidos contrários, provocando confusões ou gerando desconforto entre as pessoas.

De qualquer modo, na construção de sua gestualidade, os indivíduos incorporam (e esse conceito é bem apropriado para o que estamos tentando explicar) referências que têm a ver com sua história de vida, com a sua identidade social, com as suas relações de grupo, com a educação que recebem no ambiente familiar; enfim, com as experiências vividas na escola e no lazer, esculpindose como sujeito-corpo na relação com os outros e com o mundo.

Assim, é possível dizer que existem, pelo menos, três maneiras de compreender a linguagem corporal: há uma linguagem individual, formada a partir de uma gestualidade própria, que diz muito sobre os sujeitos, sobre seu universo 
psíquico e sobre a sua personalidade que — apesar de individual, de seu caráter pessoal - é construída na relação com a cultura; há também um conjunto de marcas, normas, regras e expressóes gestuais que perpassam a linguagem corporal dos grupos e das pessoas que compartilham de uma mesma cultura; e há, por sua vez, as práticas ou manifestações da cultura corporal que, ao serem sistematizadas e elaboradas com base em saberes e interesses específicos, isto é, como modelos de educação do corpo, comportam sentidos e significados que contextualizam, explicam, classificam e selecionam movimentos, ações, expressões e atividades corporais humanas.

Desse modo, faz sentido analisar historicamente como a ginástica e a dança se inserem na sociedade, pois isso as caracteriza como manifestaçôes sistematizadas da cultura corporal e nos permite reconhecê-las no processo de construção das ações humanas e também de sua apropriação no espaço escolar.

\section{Dimensões expressivas da ginástica e da dança}

A ginástica e a dança são manifestações da cultura corporal que hoje integram o universo das linguagens artísticas contemporâneas, compondo, como já ressaltamos anteriormente, um denso registro de saberes, gestos, sentidos e significados que, de alguma forma, exprimem e permeiam a realidade complexa em que vivemos.

A ginástica, tal como a identificamos na atualidade, é originária do século XIX, momento em que foram elaborados novos projetos educativos voltados à consolidação das sociedades burguesas, nos quais ganharam importância e destaque o corpo, o movimento, os comportamentos e as práticas corporais. Pensada como uma pedagogia do gesto e da vontade (Soares, 1998), a ginástica representou a constituição de um modelo de "educação do corpo", cuja finalidade era forjar corpos aprumados, limpos, fechados e acabados, portando uma feição reta, rígida e vertical, cuja máxima expressão pode ser visualizada pela noção de estética da retidão e da verticalidade (Soares, 2001).

Possuindo em seu interior princípios de ordem e disciplina coletiva que deveriam ser potencializados, a ginástica desenvolveu-se como um instrumento de moldagem e adestramento do corpo, estabelecendo padrões de normalidade e comportamento que deveriam exibir o projeto de civilidade almejado pela burguesia urbana e industrial que se tornava hegemônica. Além disso, vinculada aos cânones científicos da época, foi sistematizada e divulgada como um conjunto de preceitos e normas de bem viver, internalizando a necessidade de ordem, de disciplina e de utilidade das açóes e dos gestos, noções estas fundamentais a uma sociedade que se pretendia moderna, científica e produtiva. 
Vale ressaltar que a ginástica, antes desse período, era associada a um conjunto amplo de exercícios corporais, envolvendo corridas, jogos, lutas, cantos, dentre outras atividades, inclusive a dança. Porém, do século XIX até os dias de hoje, diferentes foram os desdobramentos dessa forma de educação do corpo em que a ginástica se tem feito protagonista. Dela própria foram derivadas diferentes modalidades, estilos e versões, embora continuem vivas suas características essenciais, seu conteúdo e sua forma (Marcassa, 2004). Entretanto, o desafio que se coloca na atualidade, ao pensarmos na ginástica, diz respeito não só aos princípios, aos valores e aos saberes por ela engendrados, mas também às possibilidades de acesso a ela, de seu conhecimento, sua experimentação, seu ensino e sua democratização como uma prática cultural.

No que diz respeito à dança, existem registros que a identificam como uma das primeiras manifestações artísticas do ser humano, nas quais, através de seu movimento, eram simbolizados rituais e evocaçóes sobre diferentes esferas da vida. Para Bourcier (2001), as primeiras representações de dança deram-se no campo do sagrado; ela está ligada, portanto, a atos e cerimônias. Posteriormente, foram reconhecidos os laços entre danças guerreiras, rituais agrários e danças totêmicas.

Mas seria entre os séculos XIV e XV que surgiriam os primeiros documentos escritos sobre dança: registros da dança metrificada que se afastava da dança popular na França e começava a configurar a dança de corte. Esta viria a ser a base inicial do que hoje reconhecemos como balé clássico, que teve seu auge no século XVIII, quando da criação do balé romântico.

Isso nos permite entender o papel determinante, na história da dança, do repertório clássico, que codificou todo o seu movimento, tendo sido o balé clássico considerado como "A dança" e tendo seu ensino fortalecido, no século XX e na atualidade, um modelo de corpo, de mulher e de arte que tem na pureza e na leveza os seus símbolos mais evidentes.

A inserção da dança em diálogos educacionais, no entanto, só se deu, no mundo ocidental, no século XX, quando das discussóes acerca da "dança criativa", "dança educativa" ou "dança-educação", que foram aceitas como similares no processo de educação de crianças no contexto escolar. A primeira veio de um termo difundido nos países de língua inglesa - creative dance -, segundo a qual os alunos "devem colocar seu eu nos processos de configuração de gestos e movimentos" (Marques, 1999). Os termos "dança educativa" e/ou "dança-educação", vieram de Rudolf Laban, coreógrafo e dançarino, que se contrapôs à técnica rígida e mecânica do balé clássico.

No Brasil e em outros países latino-americanos, como a Argentina, elas seriam denominadas "expressão corporal" ou "dança expressiva", porém com pouca inserção nos espaços educacionais. Prova disso é a recente - e em al- 
guns países ausente - inserção da área de Artes no currículo escolar, além da pouca inserção da dança também na educação física, que teve os conteúdos da ginástica e esporte privilegiados historicamente.

Entretanto, tendo em vista a permanência, até os dias de hoje, do modelo tradicional-tecnicista no ensino da ginástica e a ausência do ensino da dança, na escola; dos modelos de ginástica esportiva e ginástica como fitness e do modelo clássico da dança, fora da escola, algumas perguntas se fazem necessárias: até que ponto é possível promover uma educação do corpo - através da ginástica e da dança - que supere os interesses ditados pela manutenção de ordem, de adestramento do corpo, de controle moral; pelos comportamentos, de ordem, de disciplina; e pela afirmação da ideologia dominante? Em que medida e de que forma o conhecimento da ginástica e da dança tem sido tratado como conhecimento da educação física escolar? Quais as alternativas existentes quanto ao contato e à experimentação dessas práticas corporais? Será que a abordagem da ginástica e da dança nos diferentes ambientes em que elas podem estar presentes permite que seus praticantes ampliem sua visão de mundo e compreendam a expressão corporal como linguagem? E — o mais importante — será que as propostas educativas existentes têm considerado a educação do corpo como uma dimensão constitutiva da formação humana?

$\mathrm{Na}$ tentativa de responder a tais indagações, algumas hipóteses podem ser levantadas. Primeiro, não temos visto, nas propostas educativas, uma valorização adequada da dimensão corporal, o que indica que o corpo e suas linguagens - como se não fizessem parte da realidade e não precisassem ser tomados como objetos de educação - têm sido negligenciados pelos processos educativos.

Segundo, o que se percebe em relação à ginástica e à dança, é que, quando elas estão presentes na escola, aparecem de forma limitada, muitas vezes reproduzindo técnicas e movimentos estereotipados, sem reflexão ou conexão alguma com os sentidos e os valores a elas inerentes.

Terceiro, é por demais conhecida a necessidade de superarmos a visão esportivizada da ginástica, uma vez que a sua prática tem privilegiado a formação de atletas, incluindo aqueles considerados mais aptos ou mais habilidosos e excluindo o diferente como se fosse desigual, independente de sua natureza. Assim também acontece com o modelo de dança clássica, que privilegia o balé, cujos princípios técnicos exigem uma rígida conduta de repertório de movimentos que exclui essencialmente os indivíduos do sexo masculino - apesar de sua presença nas artes - e a maioria das mulheres sem um perfil longilíneo, magro e suave. Há ainda os casos em que a valorização do repertório popular é entendida como sendo a única necessária ao espaço escolar, ampliando o falso debate ou o conflito entre popular e erudito. 
Este quadro parece-nos desafiador. E é acreditando na possibilidade de oferecer ricas e diferentes experiências envolvendo a ginástica e a dança na escola que apresentamos a seguir um conjunto de orientações pedagógicas que nos têm sido úteis para o trabalho educacional com ambas, entendidas como linguagens do corpo.

Possibilidades educativas para a abordagem das linguagens da ginástica e da dança

Se o corpo possui uma linguagem, torna-se necessário, em face de uma ação educativa, decifrar e revelar o seu discurso que, como outras linguagens, não é tão evidente e, por isso, não se chega a ele com mera espontaneidade. Para que seja possível a percepção de que o corpo possui uma narrativa simbólica e culturalmente construída, parece importante revisar, então, as marcas e as impressões que se registram sobre as várias dimensões da linguagem corporal. É, então, neste momento que recorremos a um conjunto de ações e elementos que nos permitam reconfigurar a identidade da ginástica e da dança, percebendo os elos que elas estabelecem com outras práticas, bem como os sentidos específicos que constituem a gestualidade de cada uma.

O gesto contém forças reveladoras de um poder de persuasão impossível para a palavra. Ele põe em jogo todos os sentidos não só de quem o executa, mas também de quem o observa. Os gestos permitem um reconhecimento da pessoa em suas dimensões moral e psicológica, pois, conforme Revel, sendo signos, podem organizar-se numa linguagem (Soares, 2001, p.111112).

Para decifrar a linguagem do corpo é preciso revelar e (re)construir as narrativas corporais, a começar do questionamento sobre os padróes de comportamento e os significados das práticas corporais internalizadas em nossa cultura corporal, até a recuperação, na memória corporal viva, individual e coletiva, das experiências marcantes e dos saberes corporais prévios. Trata-se de uma tentativa de revisão da história do corpo "em movimento" - tanto do ponto de vista do indivíduo que a carrega, como da relação dessa mesma memória com a cultura e a sociedade mais ampla. Esse "diálogo" realizado na e pela linguagem do corpo possibilita, por sua vez, não somente conhecer mais de si mesmo e do mundo que nos cerca, mas criar novas possibilidades de expressão, inserção e intervenção em nosso meio.

O que se observa, de modo geral, é que, quando solicitamos aos alunos e alunas que recuperem suas experiências corporais mais significativas e utilizem 
tais referências como ponto de partida para a criação e a exploração de movimentos ginásticos expressivos, por exemplo, as aprendizagens corporais prévias que mais aparecem se relacionam ao universo da cultura esportiva, porém de forma ainda desarticulada dos valores, dos significados, dos conceitos e das classificações que cercam tais ações, aparentemente neutras e descoladas do contexto em que são criadas.

Isso nos leva a crer que o momento da revelação e reconstrução das narrativas corporais é de fundamental importância para que os alunos tomem consciência de suas próprias características, de seus limites e de suas qualidades corporais, podendo compreender o contexto em que foram produzidos tais registros e saberes; que sentido tinham; de que forma isso ocorreu; e qual a finalidade de certas práticas. Esse é um trabalho que envolve não só muito debate e reflexão sobre a história, a cultura e a sociedade brasileira, mas também atividades práticas nas quais os elementos constitutivos dessas aprendizagens anteriores possam ser explicitados, revelados, conhecidos, experimentados e reconstruídos.

A análise das narrativas impressas nas práticas corporais nada mais é que um processo de identificação da dramaturgia, da imagética e da escritura do corpo. Podemos reconhecer os sentidos e os significados impregnados, de um lado, na manifestação cênica da cultura corporal; de outro, nas formas como o corpo vem sendo representado, desenhado, documentado, teorizado e tecnologizado em sua produção e em seu registro. Contudo, este momento pedagógico (teórico-prático) é também catalisador e criador de novas experiências corporais, descobertas e possibilidades de revalorização e ressignificação das práticas corporais.

Portanto, uma abordagem crítica e criativa da ginástica e da dança na escola deve, além de provocar um diálogo com a cultura corporal e sua linguagem (cênica, imagética e escrita), possibilitar também a vivência de suas variadas expressōes, explorando diferentes materiais, técnicas e tecnologias. No caso da ginástica, suas várias modalidades: artística, rítmica, acrobática, bem como a presença de elementos da dança, do circo, da capoeira, dos jogos, das lutas, enfim, das várias manifestaçôes constitutivas da cultura corporal que, ao serem incorporadas à criação de coreografias, são recodificadas pela linguagem gímnica, isto é, transformadas em movimentos ginásticos.

No caso da dança, constatamos a necessidade de conhecer um universo mais amplo de referências; de desmistificar sua imagem como apenas um elemento ou um espetáculo folclórico, normalmente de caráter contemplativo. Buscamos entendê-la como conhecimento significativo para as nossas ações corpóreas, que podem ser exploradas pelo universo de repertórios: o popular, o folclórico, o clássico, o contemporâneo, etc., bem como pela improvisação e pela composição coreográfica (Brasileiro, 2001). 
Além disso, deve-se prever a confecção e a exploração de materiais alternativos - porém não substitutivos aos equipamentos oficiais, no caso da ginástica -, explorando bastões, cordas, jornais, elásticos, sombrinhas, bambus, toalhas, lençóis, caixas, travesseiros, paredes, fitas, objetos de arte, etc. Manipulados de acordo com os fundamentos e os movimentos específicos da ginástica, acabam se tornando, também, elementos cênicos do processo de composição coreográfica ou são explorados em um processo de improvisação e/ou composição coreográfica na dança.

É fundamental também pensar a fusão das linguagens artísticas às práticas corporais: com a música, na produção de sons através do corpo e da construção de instrumentos musicais, especificamente no trabalho com o ritmo; com as artes plásticas ou visuais, no trabalho com a criação de cenários e figurinos, isso para não falar da própria linguagem visual revelada a partir das coreografias; e com as artes cênicas, uma vez que a interpretação e a representação de personagens, idéias e sentimentos dá a dramaturgia necessária a um processo de criação.

Nesse caminho, consideramos a tematização como o eixo central da proposta pedagógica. A tematização é concebida como a problematização de situações que dialoguem com o contexto - aqui concebido não como objetivo, mas como interlocutor da nossa prática educativa - no qual estamos inseridos, ressaltando que a escolha do contexto dos alunos não deve ficar apenas no interesse motivacional, mas também na possibilidade de que exponham e elucidem os significados que cercam a nossa sociedade.

Os movimentos expressivos podem inspirar e enriquecer as possibilidades de movimento e de criação coreográfica. Os conteúdos são ligados uns aos outros e são constantemente relembrados de acordo com as necessidades dos alunos e das alunas, já que esses podem interferir diretamente no planejamento das aulas.

O processo de criação é uma característica importante que se dá por meio de processos de improvisação e/ou coreográficos, na intenção de representar através de movimentos ginásticos, expressivos e de dança - situações cotidianas, de atividades corporais que estimulem a criatividade que, por não ser inata ao ser humano, precisa ser desenvolvida. Além disso, o trabalho de criação é um elemento constante nesta proposta, tanto pelos resultados que é capaz de promover a médio e longo prazo em termos de expressão cênica e de capacidade de comunicação dos conteúdos desejados, quanto pela presença de preconceitos que aos poucos vão sendo superados à medida que entram em confronto com as novas concepções de corpo, de homem, de mulher, de mundo e de sociedade colocadas pela prática da dança e da ginástica. Além disso, esses processos poderão ser utilizados como síntese dos trabalhos produzidos numa aula, numa oficina, num seminário, num festival e para além da escola. 


\section{Considerações finais ou novas possibilidades}

Neste texto procuramos destacar a ginástica e a dança e algumas possibilidades pedagógicas de abordagem dessas práticas corporais no contexto educacional. Porém reconhecemos que se faz necessário refletir sobre a construção e a sistematização qualificada de novas propostas, envolvendo outros conhecimentos da cultura corporal, pois um projeto crítico de formação humana requer uma preocupação com todos os domínios do ser humano, inclusive o corporal. É nele que apostamos e inserimos a ginástica e a dança como conhecimentos constitutivos da educação do corpo.

Acreditamos que esta proposta pode e deve ser abraçada pela educação física atual, na medida em que as experiências relacionadas à ginástica e à dança, tratadas como manifestações culturais constitutivas e constituintes da totalidade social na qual vivemos, propiciam que os indivíduos compreendam a realidade que os cerca, os valores instituídos, as relações criadas. Além disso, permitem ao sujeito dar sentido próprio às suas exercitações ginásticas e às suas danças, ampliando seu conhecimento sobre si mesmo, sobre a sua gestualidade e sobre suas qualidades corporais.

Somando-se ainda a exploração e a pesquisa de movimentos expressivos, verifica-se que diferentes possibilidades de movimento vão, aos poucos, formando e complexificando o vocabulário corporal individual, bem como os repertórios que a dança e a ginástica já acumularam, contribuindo para a organização e a sistematização do saber sobre as linguagens do corpo que, nesse caso, contêm um duplo caráter. Segundo Bracht (1997), um saber que se traduz por um "saber-fazer" e um "saber-sobre" esse realizar corporal, ambos proporcionados pela prática da ginástica e da dança. Queremos dizer com isso que há dimensões da aprendizagem relacionadas às linguagens corporais que somente são passíveis de serem propiciadas pela execução de gestos, pelo ato de movimentar-se e de expressar-se e que, portanto, dificilmente podem ser descritas, explicadas ou racionalizadas. É assim que, retomando Bracht (1997), podemos falar em uma tentativa de ampliação do conceito de linguagem corporal como sendo aquele que não é nem só pensamento, nem só movimento, mas "movimento-pensamento".

\section{Referências bibliográficas}

BARBOSA, Ana Mae. A imagem no ensino de arte. São Paulo: Perspectiva, 1999.

BOURCIER, Paul. História da dança no Ocidente. 2. ed. São Paulo: Martins Fontes, 2001.

BRACHT, Valter. Educação Física: conhecimento e especificidade. In: SOUZA, Eustáquia Salvadora; VAGO, Tarcísio Mauro (Org.). Trilhas e partilhas. Belo Horizonte: Cultura, 1997. p.13-23. 
A constituição das teorias pedagógicas da Educação Física. Caderno CEDES Corpo e Educação - Centro de Estudos Educação e Sociedade (CEDES), Campinas, n. 48, p.69-88, 1999.

BRASILEIRO, Lívia Tenorio. O conhecimento no currículo escolar: $\mathrm{O}$ conteúdo dança em aulas de Educação Física na perspectiva crítica. 2001. Dissertação (Mestrado) — Universidade Federal de Pernambuco, Recife, 2001.

COLETIVO DE AUTORES. Metodologia do ensino da Educação Física. São Paulo: Cortez, 1992.

FERREIRA, Sulei (Org.). O Ensino das artes: construindo caminhos. Campinas: Papirus, 2001.

GONÇALVES, Maria Augusta Salim. Sentir, pensar, agir: corporeidade e educação. Campinas: Papirus, 1994.

HILDEBRANDT, Reiner. Concepçôes abertas no ensino da Educação Física. Rio de Janeiro: Ao Livro Técnico, 1986.

MANACORDA, Mario Alighiero. Marx e a pedagogia moderna. São Paulo: Cortez; Autores Associados, 1991.

MARCASSA, Luciana. Metodologia do ensino da ginástica: novos olhares, novas perspectivas. Revista Pensar a Prática — Universidade Federal de Goiás, Goiânia, v. 7, n. 2, p.171-186, jul./ dez., 2004.

MARQUES, Isabel. Ensino de dança hoje: textos e contextos. São Paulo: Cortez, 1999.

MAUSS, Marcel. As técnicas corporais. In: MAUSS, Marcel. Sociologia e antropologia. São Paulo: EDUSP, 1974. p. 209-221.

RODRIGUES, José Carlos. O corpo liberado? In: STROZENBERG, I. (Org). De corpo e alma. Rio de Janeiro: Comunicação Contemporânea, 1987.

SAVIANI, Dermeval. Educação: do senso comum à consciência filosófica. 12. ed. Campinas: Autores Associados, 1996.

SNYDERS, Georges. A alegria na escola. São Paulo: Manole, 1988.

SOARES, Carmen. Imagens da educação no corpo. Campinas: Autores Associados, 1998.

. Corpo, conhecimento e educação: notas esparsas. In: SOARES, Carmen (Org.).

Corpo e história. Campinas: Autores Associados, 2001. p.109-129.

Recebido em 29 de fevereiro de 2008 e aprovado em 22 de agosto de 2008. 